\title{
Prescriptive Training Courseware: IS-Design Methodology
}

\section{Elspeth McKay}

RMIT University

elspeth.mckay@rmit.edu.au

\section{Abstract}

Information systems (IS) research is found in many diverse communities. This paper explores the human-dimension of human-computer interaction (HCI) to present IS-design practice in the light of courseware development. Assumptions are made that online courseware provides the perfect solution for maintaining a knowledgeable, well skilled workforce. However, empirical investigations into the effectiveness of information technology (IT)-induced training solutions are scarce. Contemporary research concentrates on information communications technology (ICT) training tools without considering their effectiveness. This paper offers a prescriptive IS-design methodology for managing the requirements for efficient and effective courseware development. To develop the methodology, we examined the main instructional design (ID) factors that affect the design of IT-induced training programs. We also examined the tension between maintaining a well-skilled workforce and effective instructional systems design (ISD) practice by probing the current ID models used by courseware developers since 1990. An empirical research project, which utilized this IS-design methodology investigated the effectiveness of using IT to train government employees in introductory ethics; this was a study that operationalized the interactive effect of cognitive preference and instructional format on training performance outcomes. The data was analysed using Rasch item response theory (IRT) that models the discrimination of people's performance relative to each other's performance and the test-items' difficulty relative to each test-item on the same logit scale. The findings revealed that IS training solutions developed using this IS-design methodology can be adapted to provide trainees with their preferred instructional mode and facilitate cost effective eTraining outcomes.

Keywords: Information systems (IS)-design; instructional design; instructional systems design (ISD); prescriptive courseware IS-design; workplace training; first principles of instruction; goal-based training education; component display theory (CDT); learning theory; training assessment; item response theory (IRT); Rasch model

\section{Introduction}

Keeping up with information technology (IT) and communications are key challenges facing the business sector (Ma, Fildes, and Huang 2015) and leveraging IT is critical to business success (Benac 2015). Even though substantial investments are continually being made, business leaders complain about the time it takes to implement efficient and effective IT solutions. When their long-awaited training product finally arrives, it is not agile enough to keep pace with rapidly evolving strategic business goals (Rohde et al. 2016). Government agencies also have an interest in maintaining well-skilled and knowledgeable employees, and face the same problems (D'Amours and Legault 2013).

Training expenditure varies worldwide (Görg and Strobl 2006). For instance, in 2013 (North America) corporations and government spent US\$141.7Billion on training; this equates to US\$7 for every US\$1,000 in company revenues (Harward 2014). North America and Europe 
are amongst the top spenders, with Asia and India outspending Australia, South America and Africa (Harward 2014). The global market for training reached US\$306.9Billion in 2013 (Harward 2014) (see Table 1).

\begin{tabular}{|lcc|}
\hline \multicolumn{1}{|c}{ Country } & US\$Billion & Percentage of Global Market \\
\hline North America & 141.7 & 46 \\
Europe & 89.0 & 29 \\
Asia & 31.0 & 10 \\
India & 21.5 & 7 \\
Australia & 9.2 & 3 \\
South America & 6.3 & 2 \\
Africa & 3.6 & 1 \\
Rest of world & 4.6 & 1 \\
\hline
\end{tabular}

Table 1 - Global training expenditures, 2013

Many factors influence organizations' spending on training, but the most important are their size and the industry in which they operate. In 2013, organizations with fewer than 500 employees spent an estimated average of US $\$ 1,888$ per employee, with midsize organizations (500 to 9,999 employees) spending US\$838 and large organizations (10,000-plus employees) with similar training expenditure (Miller 2014).

It is more difficult to find accurate government agency training metrics. Government agency training data typically appear in report appendices, with sketchy details of the organizations involved and little detail (Shelly and Jackson 2009). This is because such training practice metrics, are distributed among the partnerships that develop between technical and vocational education and training (TVET) organizations, private industry operators and government enterprises (Spencer 2014);(ACCI 2011);(FLAG 2007 July). Marketing companies link online IT training environments to the currently popular concept of knowledge management, thereby attracting government agency sponsorship of their digital products. This understandable attraction results in the propensity for non-government training operators to cash in on the procurement of government Web-services and media support (MENA 2015).

In the government sector, there is often no agreement amongst the various stakeholders as to which one takes on ICT training resource ownership (McKay et al, 2007). Finding the right solution for ICT-based training is complicated by the multi-disciplinary mix of expertise that is required to synthesize eLearning governance and training implementation. After all, these decisions involve the diverse nature of IS practice such as: electronic commerce; global and societal; HCI; information storage and retrieval; knowledge-based systems; management information systems; and systems and software engineering (Burgess, Grimshaw, and Shaw 2017). Firstly, training material should be made available to all employees and training providers who have access to a government agency's intranet. Secondly, online training materials should be available continually, so that employees can access their training materials when needed. Thirdly, the eLearning/training solutions should have different trainee skill development pathways so that novice employees can go through the full learning program in a sequential (skill-building) order (McKay \& Izard, 2015a), and more experienced employees can select relevant training modules as refreshers (Vann 2015);(Chatzimouratidis, Theotokas, and Lagoudis 2012);(Vignan et al. 2011). 
Efficient delivery of effective training programs across a diverse and widely distributed workforce is a major challenge. For example, in the Australian state of Victoria in 2006/7, over 2000 Department of Human Services staff members engaged in finance-related activities required training (McKay et al, 2007). Providing such a large workforce with traditional faceto-face training sessions for a new procedure or legislative requirement is logistically difficult and very time-consuming. In addition, traditional modes of training service struggle to meet the growing requirement for flexibility in terms of immediacy of access and a more traineecentred approach.

New employees, or someone recently transferred to a new position, frequently have an immediate need to learn specific administrative processes. However, government training courses are often filled several months in advance, forcing the employee to obtain one-on-one tuition or learn the new skill/procedure by trial and error, neither of which is efficient for the organization. Conversely, an employee may be sent on a training course to meet organizational mandates or to meet the selection criteria for a future position, without immediately putting the new skills or procedures learned into practice; this means key competencies achieved during the training are forgotten, resulting in an unsatisfactory training outcome for both the trainee and the organization (Chatzimouratidis, Theotokas, and Lagoudis 2012).

Often face-to-face training courses have difficulty catering for individual trainees' needs due to short training timeframes and large volumes of instructional material; little wonder that understanding new administrative tasks overwhelms first-time (novice) learners (Bagley and Heltne 2003). As a consequence, they have difficulty in coping with technical details, limitations of the formalized training timeframe, and peer pressure. More experienced staff previously exposed to the subject matter (or instructional content) react unfavourably to the presentation of simple concepts and repetition of familiar content, becoming frustrated and bored. Neither of these learner groups will achieve optimized learning outcomes for themselves or the organization (Vignan et al. 2011).

Some Australian government initiatives, such as TVET, successfully negotiate the IT training services divide between the government and corporate sector. Non-government training operators can realize their remunerative expectations in securing government training contracts. However, these lucrative arrangements appear to treat workforce training as oneoff stand-alone skills development exercises.

There is a near-endless supply of off-the-shelf IT training packages. Deciding which one is suitable is not easy and there can be no guarantee of employees' reactions. As a standard goal of training is to boost workplace knowledge, ideally profiling people according to age, gender and experience would be used to benchmark expectations. However, generic IT training programs are frequently put in place without adequate evidence of their suitability; one remedy is to design and build customised IT training solutions which encourage learning while doing (Kalraiya and Buddhdev 2015);(Schank 2002). Schank (2002) says this approach may become a means to an end, and it works well if there is room to let the trainees fail without any significant negative consequences for the organization. However, learning by doing can be dangerous, for instance in a healthcare environment where health and safety are core organizational goals, and it can be expensive, because people learn at different rates and failing to provide sufficient relevant cases can prevent trainees from experiencing all they need to learn (Schank 2002). 
Rosenberg (2001) was an early advocate for organizations to adopt Web-based business strategies to encourage strong partnerships with IT and workplace learning (Rosenberg 2001); more recent scholars argue that his ideas are equally relevant in today's business and government training environments (Ballew et al. 2013). However, business adoption of Webbased training solutions is negatively impacted by the instability of Internet service providers. According to Rosenberg (2001, p.152), even "...If you can get the Web to everyone, but your infrastructure is unreliable (always going 'down'), or you're using an unreliable Internet service provider (ISP), your users will become very frustrated, very fast."

To reiterate, there are not many IS-design theories that have been developed for online communities per se (Spagnoletti, Resca, and Gwanhoo 2015, Schofield 2002). The IS literature contains little research dealing with instructional systems design (ISD) pertaining to IT and government skills training courseware development. Instead, most researchers address the creation of instructional experiences with IT; using old ID models to make their IT training materials look appealing (Appendix-1: ID model review).

In this paper we seek to fill this gap by exploring a prescriptive courseware IS-design methodology, through a research study that investigated the interactive effect of instructional format and cognitive preference on government sector training performance outcomes. We examined the main instructional design (ID) factors which affect the efficiency and effectiveness of IT-induced training programs (Docq 2015) (Schank 2002). We argue that drawing on the first principles of instruction (Merrill 2002a) will empower the courseware developer to design and implement effective online courseware that meets user/trainee expectations. Simultaneously, we argue that the component display theory (CDT) (Merrill 1987) remains relevant to implementing current IT-induced training programs (Sims 2014), as it supports our prescriptive courseware IS-design methodology that novice courseware developers can follow to customize training courseware programs to target specific training requirements.

This paper presents the theoretical background required to develop a prescriptive courseware IS-design methodology, incorporating the first principles of instruction (Merrill, 2002a), and goal-based training. Then there is a review of current ID practice and models which illustrate that the original ID principles do not align well enough with modern ICT and Web 2.0 applications. To illustrate the effectiveness of the prescriptive courseware IS-design methodology, there is an example of an empirical research study that used our IS-design approach and quantified their instructional outcomes using the Rasch item response theory (IRT) which verified the results and provides the discussion and conclusion to complete this paper.

\section{Theoretical Background}

Courseware design has long been limited to the presentation of the digital artefacts in a rather myopic fashion. However, over 30 years ago David Jonassen, a professor in learning technologies and an educational psychologist, was writing about the link between effective courseware design through electronic textual displays and computer-controlled environments (Jonassen 1982). Then, in a library and information science research study, six cases of information-seeking behaviours were examined, as students used Perseus (a Greek history information database). Therefore, albeit sporadically, researchers have been trying to align IT 
delivery platforms and pedagogy principles with a blended instructional approach towards eLearning delivery modes for many decades.

\subsection{Prescriptive IS-design Methodology}

The review began by examining the commonly accepted prescriptive ID models which have been published as ID specifications or theoretical frameworks to facilitate the creation of instructional activities (Culatta 2013). Appraisal review criteria were: the model or theory; the inception date; originating researcher and further work; and evidential examples (government training, instructional systems design (ISD), ICT, and Web 2.0) (see Appendix-1).

Table 2 presents the results of the ID model review; 25 models were listed by Culatta (2013), with identification of the three objective taxonomies that align the knowledge domains of the ID models (cognitive, affective and psychomotor).

Of the seminal 25 ID models that originated through research, which largely focused on pedagogy (the process of teaching), there was no evidence that nine had survived into the new millennium. The advent of human-computer interaction (HCI), however, renewed some researchers' interest, to the extent that some of these early models form the basis of $\mathrm{PhD}$ studies. Seven models were used in government training programs, with the Knirk and Gustofson model only presented by researchers in an international conference on eLearning for a knowledge-based society, showing no evidence of applicability to modern IT (Knirk and Gustafson 1985).

\begin{tabular}{|c|c|c|c|c|c|}
\hline \multirow{2}{*}{$\begin{array}{c}\text { Total } \\
\text { number }\end{array}$} & $\begin{array}{c}\text { Eumber } \\
\text { found }\end{array}$ & $\begin{array}{c}\text { Government } \\
\text { Training }\end{array}$ & $\begin{array}{c}\text { Instructional } \\
\text { Systems Design } \\
\text { (ISD) }\end{array}$ & ICT & Web 2.0 \\
\hline 25 & 16 & 6 & 14 & 14 & 13 \\
\hline \multicolumn{7}{|c|}{ Evidential Examples - Objective Taxonomies } \\
\hline 3 & 3 & 1 & 2 & 3 & 3 \\
\hline
\end{tabular}

Table 2 - Prescriptive instructional design (ID) models

Of the 14 models that show ISD relevance, several models have been updated for modern usage. For instance, the Dick and Carey model, created in 1978, was adapted in the early 2000s (Dick, Carey, and Carey 2004) and used in face-to-face training courses (Schneider 2009). However, the literature reveals that researchers appear to have no appetite to adopt the Dick and Carey systematic design of instruction for ICT and Web 2.0 applications. In contrast, the skill acquisition strategies of the 4C-ID model were adopted for ICT and Web 2.0 tools in a 2004 study (van Merrienboer and Jochems 2004). The ASSURE model has also been adopted for ISD with ICT tools.

So far as the objective taxonomies are concerned, the evidence shows researchers applying the cognitive domain to all four ID model review categories (government training, ISD, ICT and Web 2.0). No researchers have addressed the affective domain in government training environments, and no ID researchers have addressed the psycho-motor domain in recent times (see Appendix-1). 
Prescriptive principles of ID represent a set of theoretical propositions which focus on the relationships that remain true in appropriate conditions (Sims 2014), regardless of the instructional program (set of prescribed activities) or specific instructional activity (Merrill, Barclay, and Van-Schaak 2008). Merrill, Barclay et al. (2008) attest that instructional programs will only succeed when these fundamental underlying principles are followed, including facilitating the instructional program in direct proportion to its implementation of these principles (instructional overview or fine detail), and reflecting the design of the learning/training environments and products rather than concentrating on how people will acquire knowledge and skills from these products. Following these principles can deliver success, regardless of the delivery system or instructional architecture (Clark 2003). However, a decrement in learning performance can occur if one or more of these underlying principles is not implemented (Merrill 2002a).

\subsection{First Principles of Instruction (Merrill)}

Following a comprehensive review of ID theories, models and research, Merrill (2009) abstracted a set of interrelated prescriptive ID principles. Merrill (2009) stated that:

a principle is defined as a relationship that is always true under appropriate conditions regardless of the methods or models which implement this principle. Principles are not in and of themselves a model or method of instruction, but rather relationships that may underlie any model or method. These principles can be implemented in a variety of ways by different models and methods of instruction. However, the effectiveness, efficiency, and engagement of a particular model or method of instruction is a function of the degree to which these principles are implemented. ( $p .3)$

The following ID principles (Merrill 2009) are applicable to prescriptive IS-design elements that promote successful training outcomes (see Table 3).

The demonstration principle: The trainees watch a demonstration, such as a screen-show and/or video clips. It is important for the IS-design to provide guided navigation to general information or an organizing structure for a particular instance. Further training enhancement is achievable through peer discussion and demonstration.

The application principle: The trainees apply the new knowledge to a newly defined problem. This element describes the opportunity given within an online training module to provide solutions to a newly given case study example. It is important for the IS-design to provide the trainee with corrective feedback. Further enhancements can be achieved through peer collaborations.

The task-centred principle: The trainees engage in a task-centred instructional strategy, such as providing more solutions to a given problem. Further benefits can be expected when the ISdesign sequences the training in a simple-to-complex task progression.

The activation principle: The trainees can activate relevant prior knowledge or experience. The IS-design needs to encourage the sharing of training activities with trainees who have previous experience. Enhancements can be expected when trainees have opportunities for reflection.

The integration principle: Learning is promoted when learners integrate their new knowledge into their everyday world. This element amounts to offering circumstances of 
everyday life reflections that may require the trainee to defend their newly acquired skill/knowledge with another colleague.

\subsection{Goal-based Training (Schank)}

Since Roger Schank introduced the concept of combining 'learning by doing' training with goal-based scenarios (Schank et al. 1993/1994), many training programs have adopted this approach (Biech 2015); (Clark and Mayer 2013). The theoretical basis for this work comes from the educational/social sciences fields, depicting human behaviour as devoid of the need to draw on IS-design. For instance, Schank (2002) could see the potential of Web-based training, maintaining that the quality of training was improved because it offered the possibility of 'doing' over 'telling.' Schank's concepts were further developed into key elements of a goalbased scenario (Hsu and Moore 2011) as follows below (see Table 3 for how these Shank strategies were integrated into the prescriptive IS-design methodology for managing the requirements for efficient and effective courseware development):

Learning/training goals: these refer to procedural or declarative knowledge (Brinck 2016). To understand what participants thought about their training experience, there are four levels of learning evaluation: reaction; learning; behaviour; and results (Kirkpatrick and Kirkpatrick 2007). These data are often collected at the end of the training sessions and known in the field as 'happy sheets' (Barlow 2009), and can provide enlightened insights into the training provider, the trainee's organization, and the training venue/technology.

Training mission: trainees need to buy into the training session. In other words, the mission statement must offer a realistic objective that motivates the trainee to make the decision to pursue the training goals (McGarry 2010). This communiqué equates to an attitudinal state that enables an individual to choose taking an action towards some object, person, or event, as first described by Robert Gagné (Gagné 1985).

Cover story: this element acts as a marketing tool (Pallarito 2012) to identify a motivating story or textual example that explains the need for the training mission. The cover story needs to catch the trainee's eye.

Scenario operations: these are the instructional/training activities the trainees need to perform to fulfil the training mission. Such training activities can involve anything the courseware designer believes will promote a trainee's comprehension. They may involve decision points, together with examples and non-examples (Hsu and Moore 2011) that reveal the consequences of following or not following the scenario examples described by Merrill (2002).

Resources: these relate to the information that the trainee requires to complete the training session. A goal-based training session will involve two types of resources; the first being wellorganized information such as: textual explanations; video clips; voice-over narrations; graphics; or other resources accessible to the trainees. While the second type of resource relates to the embedded training (case-study) examples/stories (Hsu and Moore, 2011).

Feedback: training resources must provide two types of feedback (Heron 2011). The first is known as formative feedback (Shute 2007) and occurs during the training activities, whereby the trainee is given the chance to practice a skill/knowledge development. Formative feedback must allow the trainee to repeat the training event until they understand the concept (Merrill, 2002). The second type of feedback is known as summative feedback and occurs at the end of the training session. 


\subsection{Principles of Instructional Design 2017}

So where is the integration of principles of ID and ISD in the year 2017? The ID research community has responded rapidly and effectively to the advent of ICT tools and smart Web 2.0 media technologies. Previous research had largely promoted pedagogical strategies that offer a common knowledge base, which provides for variation and detailed guidance for course designers when implementing Merrill's universal ID principles. However, the advent of Web 2.0 created an expansion of the way people use the Internet, most noticeably the change from passive viewing of content to engagement with interactive sites (notably social media forums) which enable collaboration.

The literature contains several courseware design theories providing guidance for ID in 2017 (see the ID model review in the Appendix-1). They are briefly reviewed in the following paragraphs.

The ADDIE (analyse, design, develop, implement, evaluate) model comprises: high-quality designs; clearly identifiable learning objectives; carefully designed content; controlled facilitator/student workloads; well-integrated media; appropriate student activities; and student performance that is indicative of the expected instructional outcomes. ADDIE works best with large numbers; it is 'front-end' loaded, meaning it concentrates most on the ID process while leaving out interactivity issues between instructors and the student/trainees; and it lacks prescriptive advice for choosing technologies, or assessment strategies.

The ASSURE model was devised to implement Gagné's events of instruction: A - analyse learners; S - state the standards and objectives; S - select the instructional strategies, technology, media and materials; $\mathrm{U}$ - utilize technology, media and materials; $\mathrm{R}$ - require learner/trainee participation; and E - evaluate and revise (Fontana 2014). ASSURE represents an ISD procedure that can be modified by teachers/trainers to suit the best instructional environment for their students/trainees.

The ILDF (integrative learning design framework for online learning) offers a practical means of shifting courseware design thinking from theory (Anderson 2008) to the design of learnercentred instructional models in the digital age (Spector 2010). The ILDF represents a systematic ID framework that supports the designing process and planning for customized instructional environments. The ILDF is based on the premise that learning is a social process.

The three ID models described above advocate the pedagogies very well, but there is no evidence that they have been sufficiently tested for their ability to promote the intricacies of the Web 2.0/ID and social learning relationships which are so necessary for successful ID in 2017. There are four other instances of ID knowledge in the literature that have stood the test of time, and therefore are worthy of inclusion amongst these recent models.

The first such instance of ID knowledge is the discovery learning community (Alfieri et al. 2011). They advocate for inquiry-based learning, as adopted by constructivist design models and championed by Mayer (Mayer 2004). The second are goal-based scenarios, which operate on the principle that people accept and apply explanations precisely if those explanations provide the information they need. The third and fourth instances of ID knowledge relate to objective taxonomies: the psychomotor domain, and the affective domain. It remains curious that current courseware designers appear to bypass the psychomotor issues for ID 2017. The affective domain provides a taxonomy that reflects the ontological hierarchy originally depicted by the principle of internalization. 
Table 3 presents the prescriptive courseware IS-design methodology that was used in the development of courseware to train government employees, which aligns with the Merrill principles of instruction (Merrill 2009) and his previous knowledge navigation strategies (Merrill 2002b) (see Appendix-2) and Schank goal-based strategies (Schank et al. 1993/1994). It articulates the sequence of courseware design steps required to create efficient and effective courseware training modules.

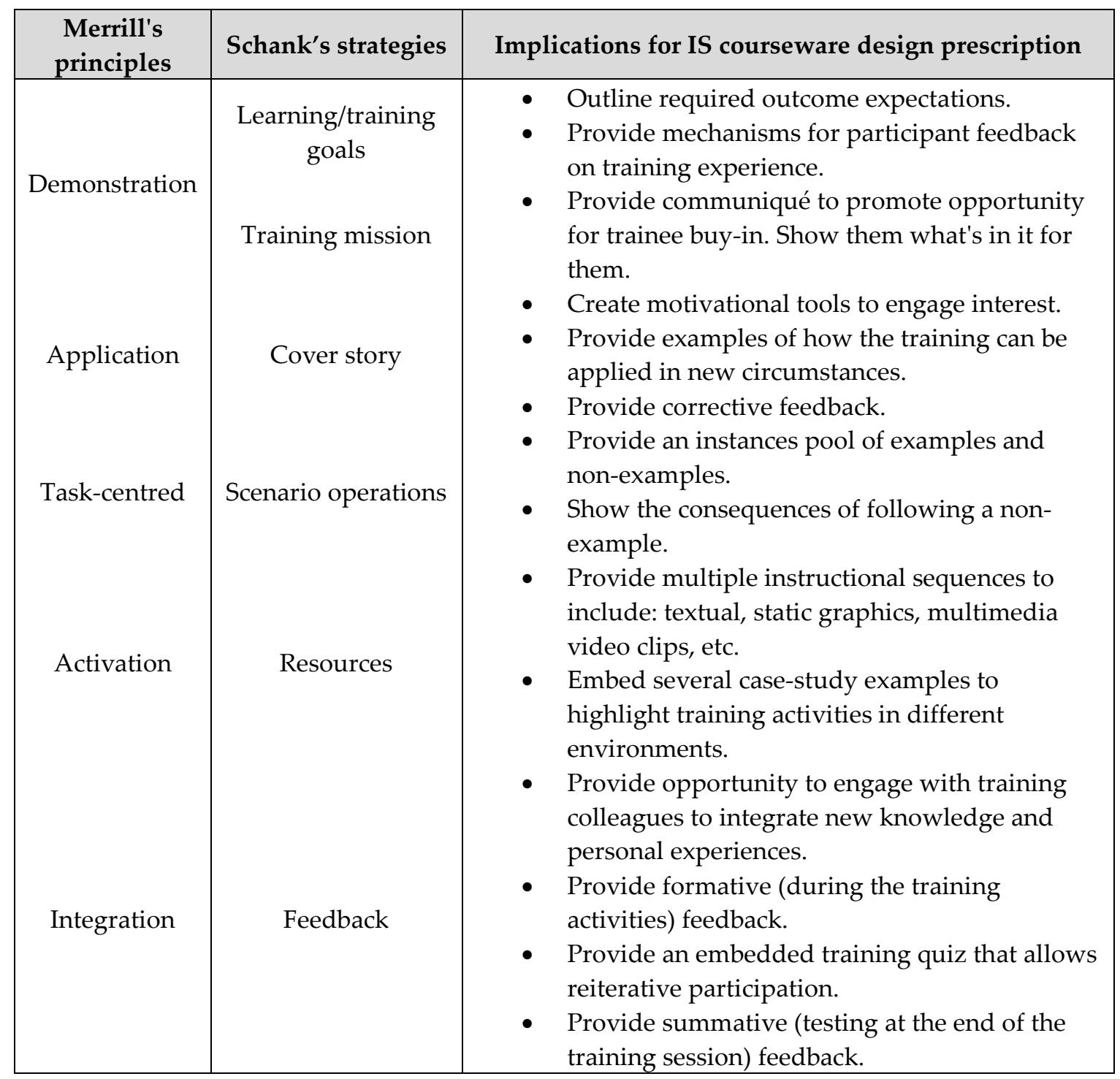

Table 3 - Combined strategies for prescriptive courseware IS-design practice

\section{Research Study Background}

The prescriptive courseware IS-design methodology was utilized in a funded research study that integrated the concepts of current IT-enabled training practice within the context of the government sector. Many providers offer training solutions to a wide range of local and global business and government customers. The theoretical frameworks that support this work largely emanate from well-established educational research (see the ID-model review, Appendix-1). Though many training programs are available online, few show evidence of consideration of the theories that underlie courseware design. 


\subsection{IT-induced Training Practice in 2017}

Understanding the visual nature of our interactions with Web-mediated training programs gives rise to knowing how different people deal with pictorial/textual content (Riding 1991). This understanding has allowed researchers from previously disparate professions to combine their expertise in multidisciplinary research projects, including: deductive theory of human action; ethics in a government agency; and healthcare practice for junior doctors (Kalraiya and Buddhdev 2015). The resulting trans-disciplinary approach to IT-induced training practice has a broadened audience of courseware design practitioners, with 'design thinking' emerging to champion the way forward with human-centred training courseware solutions (Malamed 2011). Malamed predicted that eight design trends would arise beyond 2015: design thinking; showing your work; learning experiences - not courses; micro-learning; digital badges; designing for data; crowd-sourced learning; and small private online courses (SPOCs) instead of massive open online courses (MOOCs). These eLearning/training trends address three use and context dimensions of HCI: the human-dimension, where the emphasis is on people's need for language, communication and interaction and high-levels of tactility (Solomon 2012); the computer or machine-dimension, where the technical means to provide the solution is foremost, and IT and adaption are important; and the development-dimension, which relates to design approaches leading to implementation techniques and tools.

In the human-dimension, the IT-induced training proposition of 'showing your work' can be seen when people enact Merrill's 'show me' principle. It comes about through their propensity to be continually paying attention to their mobile devices and others become interested in what they are doing. Encouraging this type of experiential sharing with IT-induced training practices prevents critical intrinsic knowledge gaps, which occur when highly skilled employees leave their organizations. Everyone benefits when people share their instructional experiences through an online (work) training environment (Malamed 2015). Boundaries for gaining new knowledge or refreshing a skill are now melting away (Bradley 2006), meaning we have reached the point where the distinction between our professional and private lives are fully integrated. Now, instead of relying upon formal training occurring in the workplace, people increasingly acquire knowledge from their mobile devices, at the time they need the information (Sellers 2013). This socialized learning/training behaviour resembles the notion of experiential learning described initially by Kolb (1984) and subsequently by Hugg et al. (2013); it reveals a preference for 'learning experiences' rather than formalized training courses (Tavangar 2014).

In the machine-dimension, the proposition of IT-induced micro-training shows we are living in an ever-shrinking digitally-enhanced world with ever-increasing connectivity expansion in which people are packing more into their daily lives and work practices (Bradley 2006). Instances of micro-learning and the consequent 'digital badges' have become commonplace (Frederiksen 2013): the daily news is delivered to us in convenient sound-bites as staged performances, while many software applications post digital badges as motivational learning/training products.

In the development-dimension of $\mathrm{HCI}$ in training, crowd-sourced examples show how people around the world are combining individual efforts to leverage expertise from joint collaborations - from designing scalable technology solutions, to improving impoverished communities, to providing expert training resources for novice courseware designers. The final example presented here relates to the controversy over the newer ID models that are 
appearing as successful IT-induced training practices - the debate over using SPOCs instead of MOOCs. The latter are free generic training programs, with cohorts of learner/trainees numbering in the thousands and a high attrition rate (Anderson 2008). In contrast, SPOCs (private and therefore likely to involve fees), typically implement a blended (or hybrid) instructional approach that involves the 'flipped-classroom' technique (Van-Praet 2016) and a small number (less than 100) of participants. This technique can vary according to the circumstances of both facilitator and learner/trainee groups. ICT tools can be engaged on an individual basis for instructional activities prior to meeting in a classroom environment and without facilitation from a teacher/trainer. The facilitator and participants then come together so that the former can answer questions and the latter can give demonstrations of newly acquired knowledge or skills that are shared amongst the cohort.

\subsection{Research Methodology}

The objectives of the example research study were to:

- $\quad$ investigate ways to encourage skill development in government administrative tasks;

- $\quad$ provide empirical evidence of the learning that occurred during an eTraining session;

- $\quad$ empower accurate vocational skills assessment;

- $\quad$ evaluate the effectiveness of State Government training programs; and

- $\quad$ promote the inclusion of ID principles into professional practice relating to Webmediated courseware design.

\subsection{Research Questions}

The main research question was:

- $\quad$ are there significant differences between the levels of skill development generated through traditional face-to-face classroom training, a blended training approach combining computerized and face-to-face instructions, and computerized/online instructional modules?

Subsequent (secondary) research questions were:

- does an individual's instructional training preference impact on their training outcome?

- does the evaluation of eTraining outcomes lead to more effective eTraining strategies?

- $\quad$ what are the effects of each specific instructional strategy on training outcomes in the corporate educational/training environment?

\subsection{Research Design}

The example research study compared the change in knowledge of 36 government sector trainees as a result of participation in a training program delivered using one of three instructional modes (McKay \& Izard 2015a). The research had a quasi-experimental 3x3 design, involving three independent variables (training mode, instructional training preference and prior domain knowledge). Cognitive performance outcomes (knowledge 
improvement from pre- to post-test) formed the dependent variable. There were three levels for each independent variable. The three instructional modes under investigation were traditional face-to-face with no computer-based materials (T-1), a blended approach involving traditional face-to-face learning and eTraining tools (T-2), and computerized eTraining (T-3). The instructional training preferences were categorised as spatial, imagery and verbal. The Object-Spatial Imagery and Verbal Questionnaire (OSIVQ) (Blazhenkova and Kozhevnikov 2009) was used to determine instructional mode preference for 25 participants (Table 4). Participants' prior domain knowledge was assessed as novice, intermediate, and experienced (operationalized when each participant underwent the knowledge/skills screening questionnaire before their training session).

\begin{tabular}{|l|c|c|c|}
\hline \multirow{2}{*}{$\begin{array}{c}\text { Cognitive Media } \\
\text { Preference } \\
\text { (OSIVQ) }\end{array}$} & \multicolumn{3}{|c|}{ Instructional Treatment } \\
\cline { 2 - 4 } & $\begin{array}{c}\text { Face-to- } \\
\text { Face } \\
\text { T-1 }\end{array}$ & $\begin{array}{c}\text { Blended T-2 } \\
\text { (combination of } \\
\text { face-to-face and } \\
\text { computerized) }\end{array}$ & $\begin{array}{c}\text { Fully } \\
\text { Computerized } \\
\text { T-3 }\end{array}$ \\
\hline Spatial & 2 & 2 & 6 \\
Imagery & 5 & 5 & 2 \\
Verbal & 1 & 0 & 2 \\
\hline
\end{tabular}

Table 4 - Main experiment participant distribution of cognitive media preferences

The researchers anticipated that cognitive processes would differ between a government employee with greater background experience and one without much experience (a novice trainee). According to Bagley and Heltne (2003), novice trainees will benefit more from instructional methods than more experienced trainees.

\subsection{Data Analysis}

Data was analysed using the QUEST Interactive Test Analysis System (Adams and Khoo 1996), a Rasch IRT modelling tool. The trainee's eLearning/training performance was evaluated based on the magnitude of change in participant proficiency (Civitello et al. 2015). It was anticipated that the analysis would identify the interactive dynamics of skill development with and without ICT tools as training mediation techniques.

\subsection{Instrumentation Validity and Marking Strategy}

To ensure homogeneity, accuracy and internal reliability of the pre- and post-testing instruments, it was necessary to calibrate all test-items. QUEST develops a uni-dimensional scale with equal intervals along each axis as it measures participants' performances and testitems together (see Figures 1 and 2). This Rasch scaling approach provides a developmental sequence of instructional/training tasks, from simple to complex (Rasch 1960). This rigorous scale identifies individuals at different skill levels, as well as locating each test-item with respect to the behaviour of the training content concepts being measured. Each question (or test-item) was given a numeric label (question numbers), and there were two scoring categories used (dichotomous and partial credit). The dichotomous scores were recorded as 0 or 1, while the partial credit items were able to receive a $0,1,2,3$ or 4 . Scores were recorded in a data file to be submitted to the QUEST tool through a command file. An earlier calibration exercise was conducted in a pilot study (McKay \& Izard 2014), to validate the scaling 
characteristics and to reflect the developmental skills' sequencing on the scale to show the training events and instructional objectives from simple to the most complex.

\section{OSIVQ Object Imagery Variable Map Run No.1}

\section{Item Estimates (Thresholds) all on all ( $\mathrm{N}=36 \mathrm{~L}=15$ Probability Levels $=.50$ )}

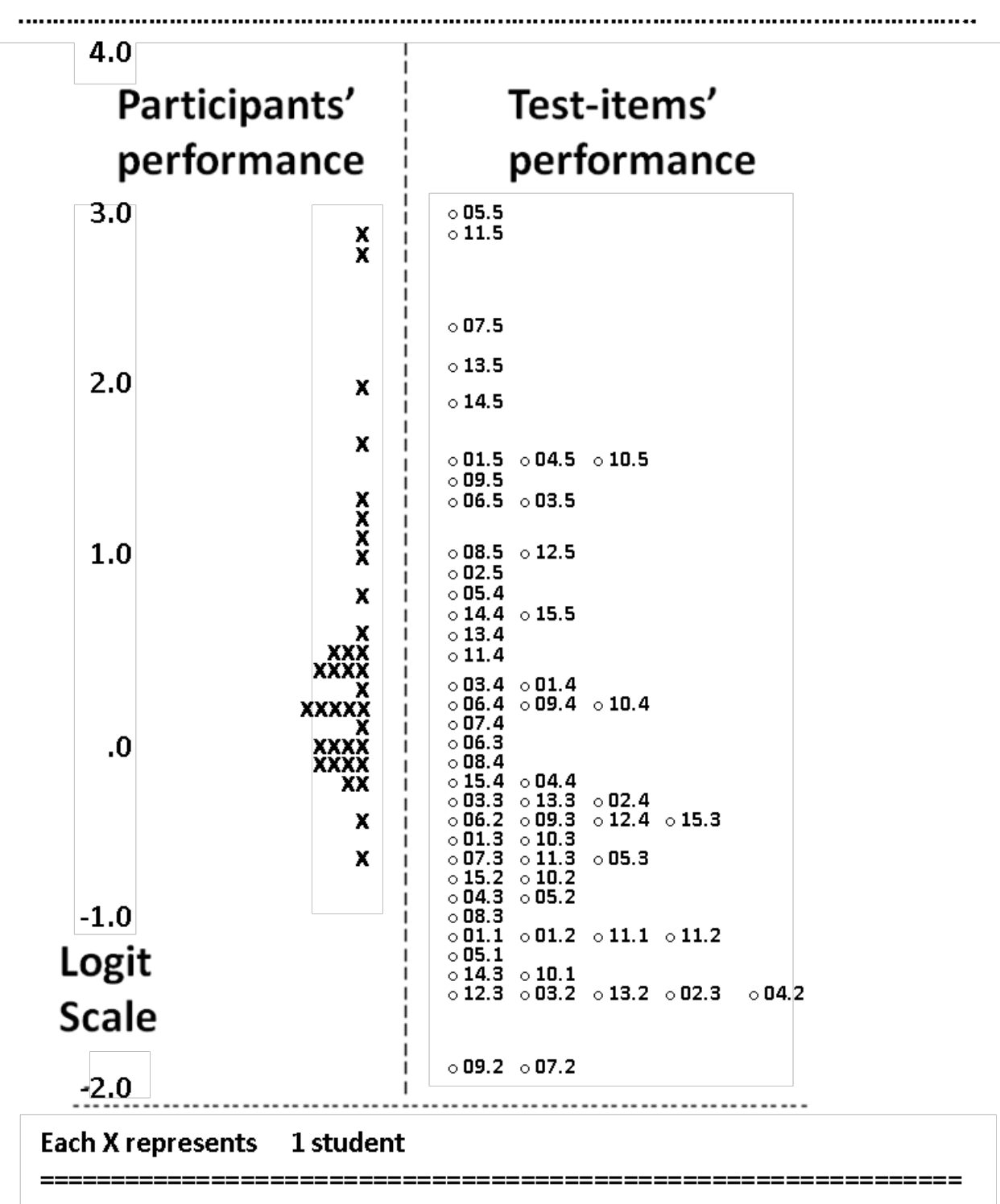

Figure 1 - QUEST variable map showing participants' and test-items' performance

Responses to the pre- and post-test-items were analysed using the Rasch model (Adams and Khoo 1996) which determines the probability of a person responding in a certain way to testitems. Each individual response to every test-item was recorded in a matrix. Where there were identical test-items on the pre- and post-tests, they were 'anchored' such that their scaled scores were comparable across the testing instruments. Using this analytical process, it was possible to determine from the difference between pre-test and post-test scaled scores whether knowledge acquisition had occurred or not, and whether the relevant training strategy had resulted in improved training performance compared against the other two instructional training treatments. 
PreTest ARC Main Control File Run No.9

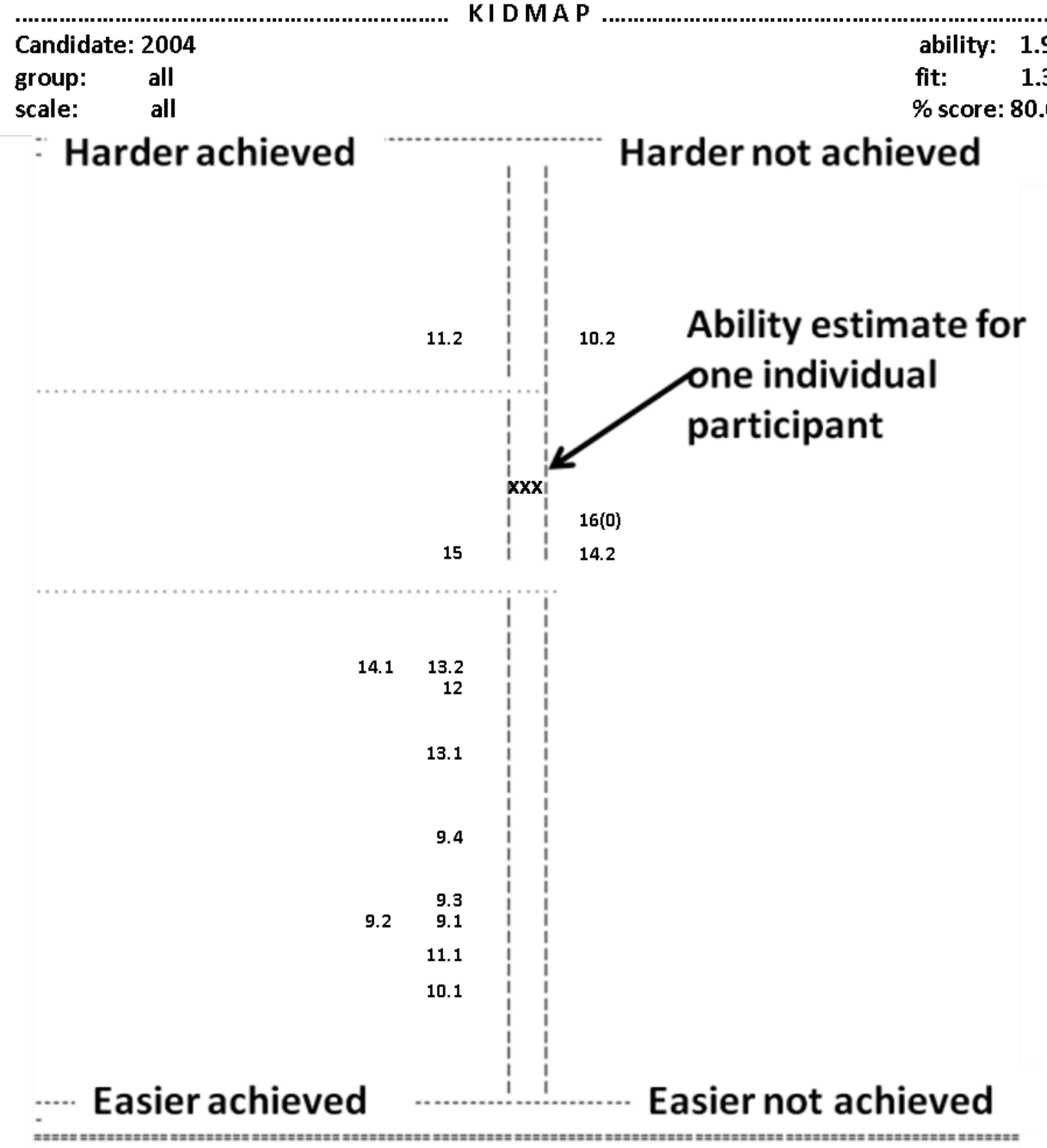

Figure 2 - QUEST kid map showing individual participant's performance

Comparisons of actual patterns of test-item interactions with participants and the Rasch model pattern becomes the fit statistic, which enables further investigation of unusual patterns. The QUEST Item Fit Map (Figure 3) provides a visual check of the magnitude of the fit statistic for the test-items that lie within the two dotted lines. The asterisks represent the magnitude of the fit statistic for the test-items on the same line (Adams and Khoo 1996). 
PreTest ARC Main Control File Run No.1

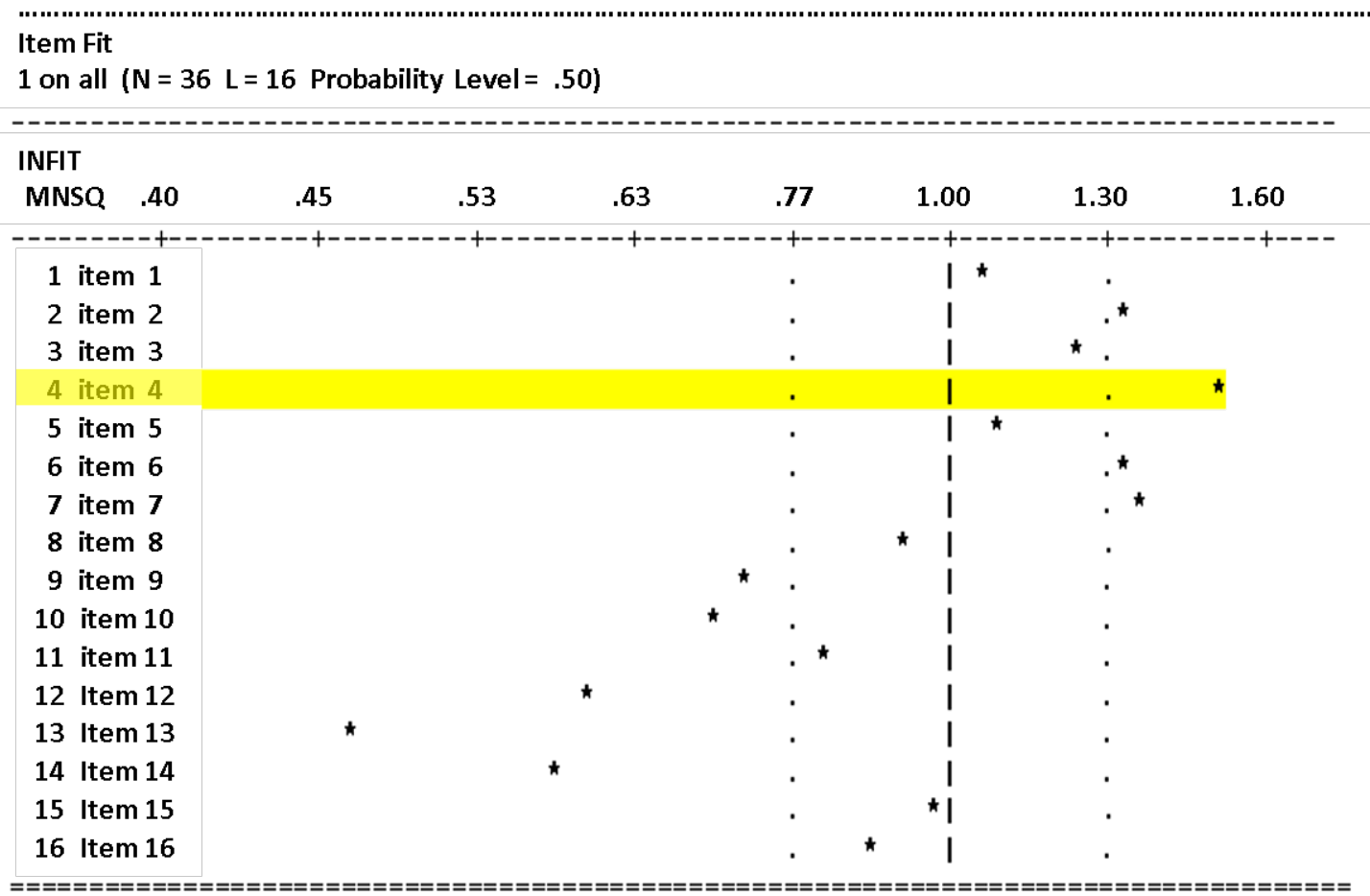

Figure 3 - QUEST item fit map showing Rasch model fit statistics

Unsuitable test-items (those outside the dotted lines) identified during the calibration exercise prompted modifications to the testing instruments for the final experiment. Subsequently, it was anticipated that both the pre- and post-test questions would be answered within an acceptable range of expectation as determined by the QUEST estimate.

In order to limit the effect of the trainees' prior domain knowledge, their pre-test scores were subtracted from their post-test scores, enabling the experiment's main cognitive performance measure to be expressed as the QUEST difference logit value (Qdlv). The mean of each training treatment sub-group's score was then calculated and compared.

\subsection{Results}

The example research study looked at the various interactive effects of variables on performance outcomes, starting with the performance outcomes compared against treatment types, followed by the interactive effect of participants' instructional training preferences.

\subsubsection{Effect of treatment type on performance}

The three training program datasets resulted from traditional facilitator-led face-to-face sessions with no computer mediation (T-1); the blended approach that involved both face-toface training and eTraining tools (T-2); and only the online eTraining tools (T-3). These datasets were comparable because they involved the same training facilitator, whose knowledge of the business process and technical competence in eLearning/training had been identified as of equally high standard to general workplace training competence. All participants were located on the logit-scale before and after the training session and were tracked for changes in status on the learning/training continuum. The resulting effect size estimates revealed gains in accomplishment for the main experiment, based on anchored scaled scores. When a test-item or a participant score is anchored, the anchor value or values apply to all subgroup 
combinations to which the test-item or participant belongs (Adams and Khoo 1996). Table 5 shows the comparison between the performance gains of the blended treatment group (faceto-face and eTraining tools T-2) and the computerized (eTraining) only group T-3.

\begin{tabular}{|l|c|c|c|}
\hline & Blended (n=7) & Comparisons & Computerized (n=10) \\
\hline Mean & 1.741 & 0.33 & 1.408 \\
Mean difference & 2.241 & & 1.825 \\
$\begin{array}{l}\text { Standard deviation } \\
\text { Pooled standard deviation }\end{array}$ & & $\begin{array}{c}2.00 \\
\text { Effect size (standard error) } \\
\text { Descriptor }\end{array}$ & $\begin{array}{c}0.16(0.49) \\
\text { Small (Izard, 2004) }\end{array}$ \\
\hline
\end{tabular}

Table 5 - Performance gains - blended group (T-2) versus computerized group (T-3)

Although the blended group (T-2) achieved a mean Qdlv that was 23\% higher than the computer only group (T-3), the effect size measure calculated for the gains in scaled score was judged to be 'small' (Izard 2004). Note that the associated standard error exceeded the effect size estimate. This means the range of the (estimate + standard error) to the (estimate - standard error) includes zero.

Table 6 shows the comparison of the computerized (eTraining) only treatment (T-3) with the face-to-face group (T-1).

\begin{tabular}{|l|c|c|c|}
\hline & $\begin{array}{c}\text { Computerized } \\
(\mathbf{n}=\mathbf{1 0})\end{array}$ & Comparisons & Face-to-face (n=8) \\
\hline Mean & 1.408 & -0.22 & 1.631 \\
$\begin{array}{l}\text { Mean difference } \\
\text { Standard deviation }\end{array}$ & 1.825 & 2.44 & 3.061 \\
$\begin{array}{l}\text { Pooled standard deviation } \\
\text { Effect size (standard error) }\end{array}$ & & $-0.09(0.47)$ & \\
Descriptor & & Very small (Izard, 2004) & \\
\hline
\end{tabular}

Table 6 - Performance gains - computerized group (T-3) vs face-to-face group (T-1)

The face-to-face training participants (T-1) scored 16\% higher on average than the computerized (eTraining) only group (T-3). However, the effect size measure calculated for the gains in scaled score was judged to be 'very small' (Izard 2004), based on anchored scaled scores. Note that the associated standard error again exceeds the effect size estimate.

Table 7 shows the final comparison -the blended group (T-2) vs the face-to-face group (T-1).

\begin{tabular}{|c|c|c|c|}
\hline & Blended $(n=7)$ & Comparisons & $\begin{array}{c}\text { Face-to-face } \\
(n=8)\end{array}$ \\
\hline Mean & 1.741 & & 1.631 \\
\hline Mean difference & & 0.11 & \\
\hline Standard deviation & 2.241 & & 3.061 \\
\hline Pooled standard deviation & & 2.71 & \\
\hline Effect size (standard error) & & $0.04(0.52)$ & \\
\hline Descriptor & & Very small (Izard, 2004) & \\
\hline
\end{tabular}

Table 7 - Performance gains - blended group (T-2) vs face-to-face group (T-1) 
The blended treatment (T-2) produced a mean score only $7 \%$ higher than that of the face-toface group (T-1), and hence the effect size measure calculated for the gains in scaled score was judged to be 'very small' (Izard 2004), based on anchored scaled scores. Note that the associated standard error exceeds the effect size estimate.

This training program on introductory ethics showed that the participants benefit most from a blended instructional treatment, where they received face-to-face instruction combined with self-exploration with an online training IS. It also showed that participant performance was worst when they only had computerized instruction.

\subsubsection{Comparative effect of OSIVQ on performance}

Did the participants' responses to the OSIVQ explain the magnitude gains in the training program (knowledge of ethics) and subsequent applications of that knowledge to the given case studies within the training materials? Assuming that the three treatments were equally effective, then the OSIVQ data may explain any gains from the pre-test to the post-test made by participants. If there was a positive relationship one would expect the highest performance gains to occur in the highest quintile on imagery, with subsequent quintiles showing lower gains. A negative correlation would expect the lowest gains to be associated with the highest quintile. However, this analysis does not show a systematic relationship between imagery and gains in participants' scores on knowledge of ethics and applications of that knowledge to the given case studies. Similar explanations, if relevant, would apply to 'spatial' and 'verbal.' It appears that there was no systematic relationship between 'spatial' and gains in score on knowledge of ethics and applications of that knowledge to the case studies. Yet it appears that there may be a systematic relationship between 'verbal' and gains in score on knowledge of ethics and applications of that knowledge to the given case studies. However, those in lower groups on the 'verbal' dimension appeared to derive greater benefit than those in the higher groups, thus a negative correlation. One has to ask why this would be so (McKay \& Izard 2015b).

Assuming that the three instructional treatments interact with the 'imagery,' 'spatial' and 'verbal' variables identified by use of the OSIVQ, then the OSIVQ data might explain the gains from pre-test to post-test made by participants in the separate training program treatment groups. Table 8 presents the correlation index of each training program treatment group alongside the three OSIVQ variables.

\begin{tabular}{|l|c|c|c|}
\hline $\begin{array}{c}\text { Performance } \\
\text { /OSIVQ } \\
\text { correlation }\end{array}$ & $\begin{array}{c}\text { Face-to- } \\
\text { Face } \\
\text { T1 }\end{array}$ & $\begin{array}{c}\text { Blended (face- } \\
\text { to-face/online } \\
\text { T2 }\end{array}$ & $\begin{array}{c}\text { eTraining } \\
\text { T3 }\end{array}$ \\
\hline Imagery & -.589 & .445 & -.004 \\
Spatial & -.149 & .039 & -.473 \\
Verbal & -.550 & .019 & -.866 \\
\hline
\end{tabular}

Table 8 - Effect of object-spatial imagery and verbal questionnaire (OSIVQ) on performance

In terms of the interactive effects of OSIVQ and training program treatment, on performance outcomes (knowledge of ethical concepts), the blended instructional treatment (T-2) involving both traditional face-to-face and eTraining tools had a positive correlation with all three OSIVQ variables. Whereas there was a negative correlation between the face-to-face treatment (T-1) and the computerized eTraining treatment (T-3) with all three OSIVQ variables. The 
correlation coefficients illustrated some expected results, such as a strong negative correlation between the computerized eTraining treatment (T-3) and the verbal OSIVQ variable, and strong negative correlation between the face-to-face treatment (T-1) and the imagery OSIVQ variable. However, there was a similar negative correlation between the face-to-face treatment (T-1) and the verbal OSIVQ variable.

\section{Discussion}

Government agencies and business organizations share the problem of how to maintain a wellskilled and knowledgeable workforce. Modifying off-the-shelf IT training packages is costly and takes a long time to organize and implement. The vexing issue for the training courseware designer is that the broad nature of the trainee demographics plays right into the hands of the non-government training providers, who offer ubiquitous programs that over-reach expectations and do not always provide effective results (Sims 2014). Although online training packages and training providers abound and, thanks to ICT, are available worldwide, the optimal solution is to provide customised in-house training with an emphasis on flexible onthe-job experiential learning. Our research indicates that part of this customization must include access to the training facilitator, either through face-to-face contact or through online interactivity.

A review of existing ID models (see Appendix-1) highlighted a lack of direction for IS courseware design strategies. IS-design pertaining to courseware developers is either missing from the literature or relies on traditional ID methodologies. However, the advent of smarter IT has made customary ID frameworks redundant. Online training packages abound, due to the borderless context of accessible ICT. There seems to be no limit to the number of training providers worldwide creating an online training plethora. And so, finding the right training package is very difficult. Far better to make your own. New frameworks, such as goal-based training, are the future.

Goal-based training fits neatly into the do-it-yourself training courseware design realm. It embraces traditional ID models to underpin online training strategies, use of new ICT tools to develop courseware, and translation of training needs into successful experiential learning.

The author set out to explore the human-dimension of HCI to present IS-design practice to innovate a prescriptive courseware IS-design methodology. The methodology combines the Merrill (2002a; 2002b; 2009) well-known ID principles and Schank's goal-based strategies (Schank et al. 1993/1994) to develop training modules. Previous researchers have used this courseware IS-design methodology to: test the interactive effect of instructional strategies and cognitive preferences (McKay 2000), in a Web-mediated environment (Mohamad 2012); to explore ICT literacy assessment tools for trainee teachers in Malaysia (Mat-Jizat 2012); and more recently to investigate mobile healthcare training practices in Jordanian hospitals (Bakkar 2016).

To illustrate the effectiveness of the prescriptive courseware IS-design methodology, an example research study was described. This research investigated the interactivity of training mode and instructional training preferences with respect to training program outcomes. Gains in introductory ethics knowledge were measured in each of three training modes (traditional classroom facilitator-led (T-1), blended traditional face-to-face and online training (T-2), and online training only (T-3)). Differences were detected in knowledge gains within the study 
groups associated with levels of government practice and demographics (job experience, gender and education).

The principal findings of the example research study showed that changes in knowledge outcomes on introductory ethics achieved a substantial magnitude of effect (Civitello et al. 2015);(Cohen 1977), across the three training treatments. The T-1 group's mean score improved by 1.63 (Tables 6 and 7), the T-2 group's by 1.74 (Tables 5 and 7), and the T-3 group by 1.41 (Tables 5 and 6). These findings are important because they vindicate the training strategies adopted by the courseware developers and strengthen the case for a customized approach to IS training design. The IS courseware design embraced the (Merrill 2002b) principles of instruction, and the six elements of Schank's goal-based training regime (Schank et al. 1993/1994), confirming the prescriptive courseware IS-design methodology for efficient and effective courseware development.

Furthermore, the study indicated that a blended instruction strategy delivers the best training performance outcomes for all learning preference groups. Hence, the results demonstrate that implementing the flipped-classroom approach in a training context effectively combines the efficiencies and practicability of online training practice with the more traditional face-to-face approach.

The analysis of the OSIVQ variable interactive effect on performance also demonstrated that the blended instructional treatment (T-2) was the only treatment with positive correlations. The strongest correlation (0.445) was between the imagery variable and the blended instructional treatment (T-2). This result suggests that the images contained within the computerized eTraining instruction, combined with face-to-face clarifications, had a positive effect on performance outcomes. As predicted, the imagery-preferenced trainees had a stronger performance correlation with the computerized eTraining instructional mode (T-3) than face-to-face (T-1), and the verbal-preferenced trainees had a stronger performance correlation with the face-to-face training mode (T-1) than the online computerized eTraining mode (T-3). The spatial-preferenced group had no strong correlation to any of the instructional treatments, however had a large negative correlation with the computerized eTraining mode (T-3). Spatial preference is a complex mix of cognitive processing that involves both object imagery (visual appearances) and spatial imagery (spatial relationships) (Blazhenkova \& Kozhevnikov, 2009), therefore it is possible that the spatial-preferenced trainees experienced imagery overload when using the computerized training mode (T-3) and benefited from interactive training instruction with the facilitator.

\section{Conclusion}

A customized eTraining program should seamlessly match each trainee's learning profile to meet their individual needs allowing each trainee to define their own knowledge/skill development path. To customize an eTraining program, a prescriptive courseware IS-design methodology is required.

This paper contributes to the field by proposing that a prescriptive training courseware ISdesign methodology can generate an efficient and effective courseware development model. The model combines Merrill's (2002a) principles of ID with Schank's goal-based 'learning by doing' training ID elements (Schank et al. 1993/1994), to provide: training goals; a training mission; a cover story; scenario operations; resources; and the all-important formative feedback. 
The example project showed that the customized prescriptive courseware IS-design methodology, combining instructional strategy, prior domain knowledge and preferred learning context could produce better outcomes than the one-size-fits-all approach to training solutions involving ICT generally applied in the government/corporate sector. The example project proved this to be true, demonstrating significant knowledge acquisition by participants. Improving government/corporate training outcomes, generating a more highly skilled workforce that will have a significant impact on business results.

\section{References}

ACCI. 2011. Employers' Commitment to Training: Key finding from the ACCI National Workplace Skills Survey (2010) Canberra, http://www.acci.asn.au/ Australian Chamber of Commerce and Industry.

Adams RJ, Khoo S-T (1996) QUEST:The Interactive Test Analysis System. Melbourne: Software User Manual. Australian Council for Educational Research.

Alfieri L, Brooks PJ, Aldrish NJ, Tenenbaum JR (2011) Does discovery-based instruction enhance earning? J. of Educational Psychology 103 (1):1-18 http://dx.doi.org/10.1037/a0021017.

Anderson T (2008) Theory and Practice of Online Learning: Issues in Distance Education, Canada: Athabasca University. doi: 9781897425077.

Bakkar MN (2016) An investigation of mobile healthcare (mHealcare) training design for healthcare empoyees in Jordan. Doctoral Dissertation (Business Information Systems) Total fulfilment RMIT Univ. School of Business Info. Tech. \& Logistics.

Ballew P, Castro S, Claus J, Kittur N, Brennan L, Brownson RC (2013) Developing web-based training for public health practitioners: What can we learn from a review of five disciplies? Health Education Research 28 (2):276-287. doi: 10.1093/her/cys098.

Barlow S (2009) Happy Sheet Template. http://www.trainingzone.co.uk/develop/cpd/happysheet-template.

Benac DJ (2015) Keeping wind in your sale: Keeping up with tools, techniques, and technology. J. of Failure Analysis and Prevention 15:1-2 doi: 10.1007/s11668-014-9915-2.

Biech E (2015) 101 Ways to Make learning Active Beyond the Classroom NJ Pfeiffer Wiley. http://au.wiley.com/WileyCDA/WileyTitle/productCd-1118971981.html.

Blazhenkova O, Kozhevnikov M (2009) The new object-spatial-verbal cognitive style model: Theory and measurement Applied Cognitive Psychology 23 (5):638-663. doi: 10.1002/acp.1473.

Bradley G (2006) Social and Community Informatics: Humans on the net. NY: Routledge: Taylor\&Francis.

Brinck I (2016) Developing an understanding of social norms and games: Emotional engagement, nonverbal agreement, and conversation. Theory \& Psychology 24 (6):737-754.

Burgess FT Grimshaw P, Shaw NE (2017) Research commentary: Diversity of the information research field: A governance perspective Information Systems Research 28 (1):5-21. 
Chatzimouratidis A, Theotokas I, Lagoudis IN (2012) Decision support systems for human resource training and development International J. of Human Resource Management 23 (4):662-693. doi: 10.1080/09585192.2011.561235.

Civitello DJ, Cohen J, Fatima H, Halstead NT, Liriano J, McMahon TA, Ortega CN, Sauer EL, Sehgal T, Young S, Rohr JR (2015) Biodiversity inhibits parasites: Broad evidence for the dilution effect Proceedings of the National Academy of Sciences of the United States of America (PNAS) 112 (28):8667-8671. doi: 10.1073/pnas.1506279112.

Clark R (2003) Six principles of effective e-Learning: What works and why The eLearning Guild's Learning Solutions: Practical applications of technology for learning - e-Magazine (Sept.):1-10.

Clark RC, Mayer RE (2013) Scenario-Based e-Learning: Evidence-Based Guidelines for Online Workforce Learning. NY.

Cohen J (1977) Statistical Power Analysis for the Behavioral Sciences. New York: Academic Press.

Culatta R (2013) Instructional Design Models http://www.instructionaldesign.org/models.

D'Amours M, Legault M-J (2013) Highly skilled workers and employment risks: Role of instutions Labor Studies J. 38:89-109.

Dick WO, Carey L, O'Carey J (2004) The Systematic Design of Instruction. 0205412742: Allyn \& Bacon.

Docq F (2015) Course design and delivery specifications as a tool for ensuring quality in an online training program Canadian J. of Learning and Technology 41 (3.1).

FLAG (2007 July) Australian flexible learning framework 2005-2007 impact statement Report to National Senior Officials Comm. Flexible Learning Advisory Group: Aust. Govt Dept of Educ, Sci. \& Training.

Fontana T (2014) The 1999 Heinich, Molenda, Russell, E Smaldina ID Model also known as ASSURE https://prezi.com/uj4u_9y1ruwa/the-heinich-molenda-russel-smaldino-model-alsoknown-a/.

Frederiksen L (2013) Best of the literature Public Services Quarterly 9:321-325. doi: 10.1080/15228959.2013.842414.

Gagné RM (1985) The Conditions of Learning: And the theory of instruction NY: Holt/Rinehart/Winston.

Görg H, Strobl E (2006) Do government subsidies stimulate training expenditure: Microeconometric evidence from plant-level data Sourthern Economic Journal 72 (4):860876.

Harward D (2014) How Big is the Training Market? Training Industry. https://www.trainingindustry.com/blog/blog-entries/how-big-is-the-trainingmarket.aspx:

Heron G (2011) Examining principles of formative and summative feedback British J. of Social Work 41 (2):276-295.

Hsu C-Y, Moore DR (2011) Formative research on the goal-based scenario model applied to computer delivery and simulation J. of Applied Instructional Design 1 (1):13-24. 
Hugg PR, Mcaulay JJ, Lorio KV, Sarpy L (2013) Experiential teaching on steriods: Unexpected pedagogical discoveries Loyola J. of Public Interest Law Loyola Univ. New Orleans College of Law Legal Studies Research Paper 2014-01 http://ssrn.com/abstract=2418366.

Izard J (2004) Impediments to sound use of formative assessment (and actions we should take to improve assessment for learning) Paper presented at the Australian Association for Research Education (AARE 2004): Positioning education research Melbourne http://www.aare.edu.au/04pap/iza04905.pdf.

Jonassen DH (1982) The Technology of Text. New Jersey: Educational Technology.

Kalraiya A, Buddhdev P (2015) The TROJAN project: Creating a customized international orthopedic training program for junior doctors Orthopedic Reviews 7 (1): 6-8.

Kirkpatrick DL, Kirkpatrick JD (2007) Implementing the Four Levels: A practical guide for effective evaluation of training programs: Berrett-Koehler.

Knirk FG, Gustafson KL (1985) Instructional Technology: A systematic approach to education: Holt Rinehard \& Winston.

Kolb DA (1984) Experiential Learning: Experience as the source of learning and development. NJ: Prentice Hall.

Ma S, Fildes R, Huang T (2015) Demand forecasting with high dimensional data: The case of SKU retail sales forecasting with intra-and inter-category promotional information European J. of Operational Research 249 245-257.

Malamed C (2015) 8 Learning Design Trends to Watch in 2015 http://theelearningcoach.com/elearning_design/learning-design-trends-2015/.

Mat-Jizat, JE (2012) Investigating ICT-literacy assessment tools: Developing and validating a new assessment instrument for trainee teachers in Malaysia Doctoral Dissertation (Business Information Systems). Total fulfilment: RMIT Univ. School of Business Info. Tech. \& Logistics.

Mayer RE (2004) Should there be a three-strikes rule against pure discovery learning? American Psychologist 59 (1):14-19 http://dx.doi.org/10.1037/0003-066X.59.1.14.

McGarry D (2010) Seven reasons people buy personal training sessions Club Industry. http://clubindustry.com/step-step/seven-reasons-people-buy-personal-trainingsessions.

McKay E (2000) Measurement of cognitive performance in computer programming concept acquisition: Interactive effects of visual metaphors and the cognitive style construct. Journal of Applied Measurement 1 (3):257-286.

McKay E, Axmann M, Banjanin N, and Howat A (2007) Towards web-mediated learning reinforcement: Rewards for online mentoring through effective human-computer interaction Proceedings of the 6th IASTED International Conference on Web-Based Education, Chamonix, p:210-215, ISBN:978-0-88986-650-8 http://www.iasted.org/conferences/pastinfo-557.html.

McKay E and Izard JF (2014) Online training design: Workforce reskilling in government agencies Proceedings of the IC3e 2014 IEEE Conference on eLearning, eManagement and Services, Melbourne, pp.70-75. 
McKay E and Izard JF (2015a) Evaluate online training effectiveness: Differentiate what they do and do not know Proceedings of the $8^{\text {th }}$ International Conference on ICT, Society and Human Beings 2015 (Multi conference on computer science and information systems MCCSIS), Las Palmas de Gran Canaria.

McKay E, and Izard J (2015b) Measurement of cognitive performance in introductory ethics: Workforce reskilling in government agencies Proceedings of the 4th IEEE Conference on eLearning, e-Management and e-Services (IC3e2015), Melaka. Bagley CA, Heltne M (2003) Cooperative teams. Collaboration Conference, Bloomington, MN.

MENA (2015) Empanelment of independent voluntary/non-government organisation as capacity building and training providers [Tender documents: T26398172]. In Watershed Development and Soil Conservation Department, edited by A Bawaba. Rajasthan: Proquest.

Merrill DM (2009) First Principles of Instruction. Instructional Design Theories and Models: Building a common Knowledge base III. NY: Routledge.

Merrill DM, Barclay M, Van-Schaak A (2008) Prescriptive principles for instructional design. In Foundations of Educational Technology: Integrative approaches and interdisciplinary perspectives, edited by J. Michael Spector, M.David Merrill, M.F. J. van Merriënboer and M.P. Driscoll. NY: Taylor \& Frances.

Merrill MD (1987) The new component design theory: Instructional design for courseware authoring Instructional Science 16:19-35.

$\begin{array}{lllllll}\text { Merrill MD (2002a) First Principles of Instruction ETRED } 50 & \text { (3):43-59 }\end{array}$ http://www.indiana.edu/ tedfrick/aect2002/firstprinciplesbymerrill.pdf.

Merrill MD (2002b) Pebble-in-the-pond model for instructional development Performance Measurement 41 (7):39-44 http://mdavidmerrill.com/Papers/Pebble_in_the_Pond.pdf.

Miller L (2014) TD 2014 State of the Industry Report: Spending on Employee Training Remains a Priority.

Mohamad M (2012) The effects of web-mediated instructional strategies and cognitive preferences in the acquisition of introductory programming concepts: A rasch model approach Doctoral Dissertation (Business Information Systems). Total fulfilment RMIT Univ. School of Business Info. Tech. \& Logistics.

Pallarito K (2012) Cover story: Head off the competition with marketing strategies that work Hearing J. 65 (7):16,18,20,22. doi: 10:1097/01.HJ0000416271.13977.8d.

Rasch G (1960) Probabilistic Models for Some Intelligence and Attainment Tests. Copenhagen: Nielsen \& Lydiche.

Riding RJ (1991) Cognitive Styles Analysis UK Birmingham Learning and Training Technology.

Rohde M, Brödner P, Stevens G, Betz M, Wulf V (2016) Grounded Design - a praxeological IS research perspective J. of Information Technology. doi: 10.1057/jit.2016.5

Rosenberg MJ (2001) e-Learning: Strategies for Delivering Knowledge in the Digital Age. NY: McGraw-Hill.

Schank RC (2002) Designing World-Class E-Learning: How IBM, GE, Harvard Business School, E Columbia University are Succeeding at e-Learning. NY McGraw-Hill. 
Schank RC, Fano A, Bell B, Jona M (1993/1994) The design of goal-based scenarios J. of the Learning Sciences 3 (4):305-345.

Schneider P (2009) The redesign of face-to-face training courses and the role of participants' feedback within the redesign process Partial fulfillment for a Doctor of Philosophy, Educ, Capella Univ. (3379722).

Schofield K (2002) On-line Learning: Case studies of the corporate experience Sydney: OVAL 192069871X.

Sellers A (2013) Growing Reliance on Smart Devices Is Influencing Consumer Behavior, According to Research From Euromonitor International http://finance.yahoo.com/news/growingreliance-smart-devices-influencing-080000376.html.

Shelly M, Jackson M (2009) Doing business with consumers online: Privacy, security and the law International J. of Law and Information Technology 17 (2):180-205. doi: 10.1093/ijlit/can003.

Shute V (2007) Focus on Formative Feedback. NJ: Educational Testing Service, Princeton https://www.ets.org/Media/Research/pdf/RR-07-11.pdf.

Sims R (2014) Design Alchemy. Switzerland: Springer.

Solomon M (2012) High-Tech, High-Touch Customer Service: Inspire timeless loyalty in the demanding new world of social commerce Saranac Lake: AMACOM. https://www.micahsolomon.com/freechapters.html.

Spagnoletti P, Resca A, Gwanhoo L (2015) A design theory for digital plaforms supporting online communities: A multiple case study J. of Information Technology 30:364-380.

Spector J M (2010) Learning and Instruction in the Digital Age. Edited by J.M. Spector, D. Ifenthaler, P. Isaias, Kinshuk and D.Sampson. 1st ed. NY: Springer.

Spencer J (2014) Policy, Business and ICT: A study of the growth and decline of private vocational training providers in the education/migration industry in Australia Doctor of Philosophy, Global, Urban and Social Sciences, RMIT Univ. (http://researchbank.rmit.edu.au/view/rmit:161511).

Tavangar H (2014) The Out of Eden Walk: An experiential learning journey from the virtual to the real http://www.edutopia.org/blog/out-of-eden-experiential-learning-homa-tavangar.

Van-Praet E (2016) Business Meeting Training on Its Head: Inverted and embedded learning Business and Professional Communication Quartely 79 (1):119-130. doi: $10.1177 / 2329490615610777$.

van Merrienboer JJG, Jochems W (2004) Integrated E-learning: Implications for pedagogy, technology and organization. London: RoutledgeFalmer.

Vann LS (2015) Demonstrating empathy: A phenomenological study of instructional designers making instructional strategy decisions for adult learners Partial fulfillment of requirements for Doctor of Philosophy, Capella Univ.

Vignan S, Senthilkumar G, Marthi N, Goeteti P (2011) Integrating learning outcomes and bloom's taxonomy in web application development course: Experiences from corporate training 2011 IEEE Students' Technology Sumposium IIT Kharagur. 
Copyright: (c) 2018 McKay. This is an open-access article distributed under the terms of the Creative Commons Attribution-NonCommercial 3.0 Australia License, which permits noncommercial use, distribution, and reproduction in any medium, provided the original author and AJIS are credited.

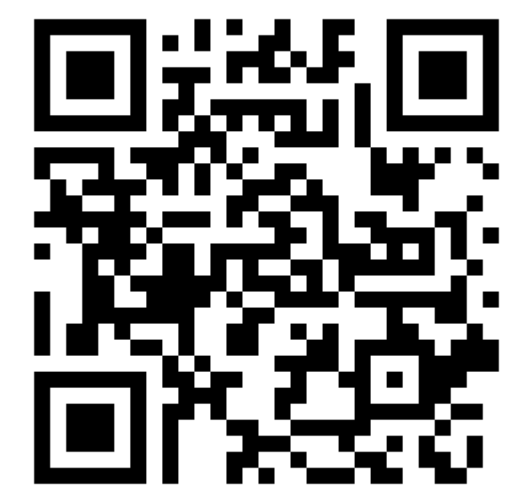

